\title{
REFLORESTAMENTO DE PINUS, COMO ALTERNATIVA DE RENDA PARA 30 PROPRIEDADES RURAIS NA REGIÃO DO SUDOESTE PAULISTA
}

\author{
NOTA TÉCNICA
}

HOFFMAM, Rocha Rubens ${ }^{1}$
DE CONTI, Andrea Cressoni
DE CONTI, Cláudio
DE
PRATES, Gláucia Aparecida $^{4}$

RESUMO: A pesquisa trata da alternativa de geração de renda com reflorestamento de pinus para 30 propriedades rurais na Região do Sudoeste Paulista. O propósito fundamental é demonstrar a viabilidade econômica e como desenvolve a implantação do reflorestamento em todas suas etapas operacionais no sentido de dar suporte, treinamento e assistência técnica ao produtor rural quanto ao manejo correto tornando-se sustentável e ambientalmente correto.

Palavras - Chave: Pinus. Viabilidade econômica. Sustentabilidade.

SUMMARY: This research deals with alternative income generation with reforestation of pine to 30 farms in the Southwest Region Paulista. The fundamental purpose is to demonstrate the economic viability and how to develop the implementation of reforestation in all its stages with an operational plan of action towards providing support, training and technical assistance to farmers on the correct management, respecting the environment, making is sustainable.

Keywords: Pine. Feasibility economical. Sustainability.

\section{INTRODUÇÃO}

A região do Sudoeste Paulista passa por sérios problemas de falta de incentivos para o desenvolvimento sustentável. Como criar novos empregos e gerar fontes alternativas de renda para os produtores rurais da região em suas propriedades para evitar o êxodo rural. Assim sendo, em algumas propriedades rurais, as atividades florestais é uma forma de incentivo de geração de renda, além do uso da mão-de-obra excedente em alguns períodos do ano, no setor rural, ou seja, na entressafra da região (ABRAF, 2008; RIBEIRO, 2008; CAETANO, 2007).

Ao incentivar os produtores rurais, já envolvidos em outras culturas a iniciarem também a implantação de florestas exóticas como outra fonte alternativa de renda, produz como resultado direto à criação de novos empregos, a melhoria da infraestrutura, além de promover o desenvolvimento sustentável na região e preservação do meio ambiente. $\mathrm{O}$ reflorestamento em áreas não nobres ou ociosas (que não interessa a agricultura ou pecuária) garante o aumento de renda na propriedade. $\mathrm{O}$ incentivo ao

\footnotetext{
${ }^{1}$ Discente do curso de administração da Faculdade de Ciências Sociais e Agrárias de Itapeva - FAIT

2 Docente do Curso de Silvicultura da Faculdade de Tecnologia - Centro Paula Souza - FATEC - Campus de Capão Bonito, andrea.deconti@fatec.sp.gov.br

${ }^{3}$ Docente do Curso de Engenharia Industrial Madeireira - UNESP - Itapeva, conti@itapeva.unesp.br

${ }^{4}$ Docente do Curso de Engenharia Industrial Madeireira - UNESP - Itapeva, Glaucia@itapeva.unesp.br
} 
reflorestamento consciente, em que a sociedade deixa de buscar madeira das reservas de florestas nativas, porque tem disponibilidade do produto gerado com o reflorestamento. A iniciativa também valoriza as pequenas e médias propriedades, fixa o homem no campo e desconcentra a renda, pois esta atividade deixa de ser explorada exclusivamente por grandes empresas (CRISTIANO, 2002; SILVA et al., 2002).

O objetivo deste trabalho foi analisar a viabilidade econômica do reflorestamento de pinus como fonte de renda em longo prazo (poupança verde) para 30 (trinta) propriedades rurais na Região Sudoeste Paulista; analisando também os investimentos de implantação e rendimento de produtividade por hectare, demonstrando a projeção de faturamento com os manejos adequados incluindo os custos diretos e indiretos, e identificando a melhor forma de implantar uma floresta dentro da viabilidade econômica conforme a mão-de-obra da região.

A Região Sudoeste Paulista é uma região que faz divisa com o Paraná, que tem um grande potencial de crescimento florestal, as espécies do gênero pinus se desenvolvem muito bem nesta região, são 32 Municípios nesta região em que os produtores rurais têm interesse em reflorestar para terem uma fonte de renda futura, tanto na madeira quanto na produção de resina. É uma região que possui forte aptidão florestal madeireira e caracteriza-se por concentrar grandes reflorestamentos e um número alto de indústrias madeireiras, fábrica de celulose e papel já instalados. Existem ainda, na região, várias instituições com tradição de pesquisa florestal e madeireira, como o Instituto Florestal de São Paulo, que conta com as Estações Experimentais de Itapeva, Itararé e Itapetininga, as estações ecológicas de Itapeva e Itaberá, o IBAMA de Capão Bonito, a Engenharia Madeireira UNESP e Engenharia Florestal da FAIT em Itapeva entre outros.

\section{MATERIAIS E MĖTODOS}

A metodologia de pesquisa usada nesse trabalho de atividades e técnicas utilizadas na coleta de dados foi através de entrevista e pesquisa de campo na sua maior parte.

Do ponto de vista de abordagem do problema, tem natureza quantitativa podendo ser quantificável ou qualificável ao mesmo tempo assumindo a forma de levantamento.

Nesse trabalho foram usados também os dados de um trabalho elaborado por uma grande empresa florestal da Região Sudoeste Paulista a Marquesa S/A que atua na área de reflorestamento com estudo realizado desde o ano 2000 com propósito de incentivar os produtores rurais da região a reflorestar suas áreas degradadas (Fomento Florestal).

\section{RESULTADOS E DISCUSSÃO}

Outros dados que foram apurados para compor esse trabalho foram as visitas a 30 (trinta) propriedades rurais, com entrevistas aos próprios produtores rurais de onde foram colhidas as informações.

A propriedade rural, em seus vários anos de existência, vem usando uma série de métodos visando atingir seus objetivos quanto à sustentabilidade na agricultura e pecuária, portanto ao desenvolver um projeto de reflorestamento, deve utilizar o planejamento operacional em função do objetivo que pretende atingir, e do assunto que pretende transmitir sabendo-se que se trata de um investimento em longo prazo com resultados positivos no seu ciclo.

Para a implantação do plano de negócio e a viabilidade econômica, considerou-se os valores realizados na região de atuação para o investimento inicial no $1^{\circ}$ (primeiro) ao $3^{\circ}$ terceiro ano que se referem às atividades que serão implantadas. 
O retorno financeiro acontece a partir do $8^{\circ}$ (oitavo) ano, na época do $1^{\circ}$ desbaste onde iniciara a $1^{\circ}$ (primeira) receita com a colheita da madeira proveniente do reflorestamento, esta madeira considera-se um aproveitamento de 08 a $18 \mathrm{~cm}$ de diâmetro destinado à celulose.

Do $9^{\circ}$ (nono) ano ao $14^{\circ}$ (décimo quarto) ano se da a $2^{\circ}$ (segunda) receita, com a exploração da resina a uma produção média de 2 (duas) a 3 (três) toneladas por hectare ano.

No $15^{\circ}$ (décimo quinto) ano, inicia-se a $3^{\circ}$ receita com o $2^{\circ}$ (segundo) desbaste onde $50 \%$ da madeira de 08 a $18 \mathrm{~cm}$ de diâmetro é para celulose e $50 \%$ de 19 a 25 de diâmetro toras que são destinados para as serrarias da região.

Do $16^{\circ}$ (décimo sexto) ano ao $20^{\circ}$ (vigésimo) ano, $4^{\circ}$ (quarta) receita com a continuação da resinagem com produção em média de 2 (duas) toneladas por ha ano.

Ao $21^{\circ}$ (vigésimo primeiro) ano, $5^{\circ}$ (quinta) e ultima receita com o corte final da floresta, sendo $20 \%$ madeira de celulose de $18 \mathrm{~cm}$ de diâmetro abaixo e $80 \%$ tora de $35 \mathrm{~cm}$ de diâmetro acima destinado às serrarias da região.

Considerando que o investimento inicial fosse aplicado no mesmo período, a uma taxa de $10 \%$ ao ano teríamos uma diferença de 3 (três) vezes menos de que investido com o reflorestamento de pinus, o gráfico 1,2 e o quadro 1 definem bem a análise da viabilidade econômica por hectare.

Gráfico 1 - Aplicação do capital inicial de 0 a 21 anos a uma taxa de $10 \%$ ao ano.

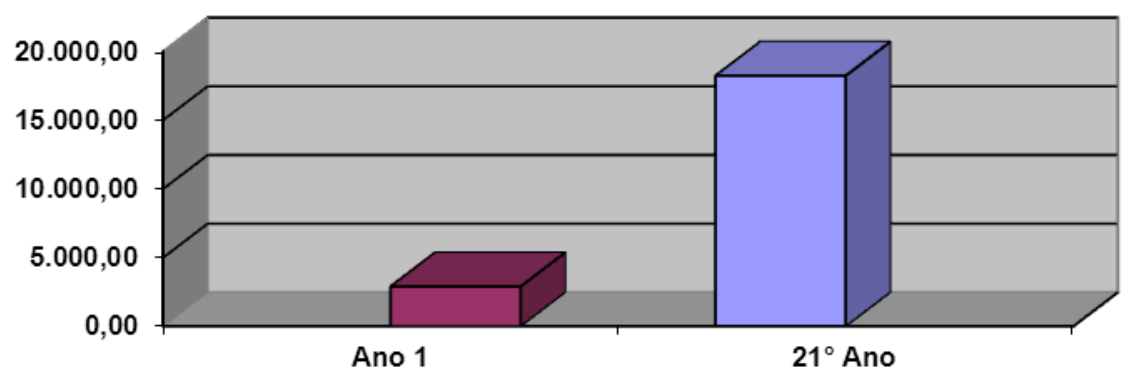

口Retorno Financeiro

口Investimento Inicia

Fonte: Elaborado pelos autores.

Gráfico 2 - Aplicação do capital inicial de 0 a 21 anos com reflorestamento.

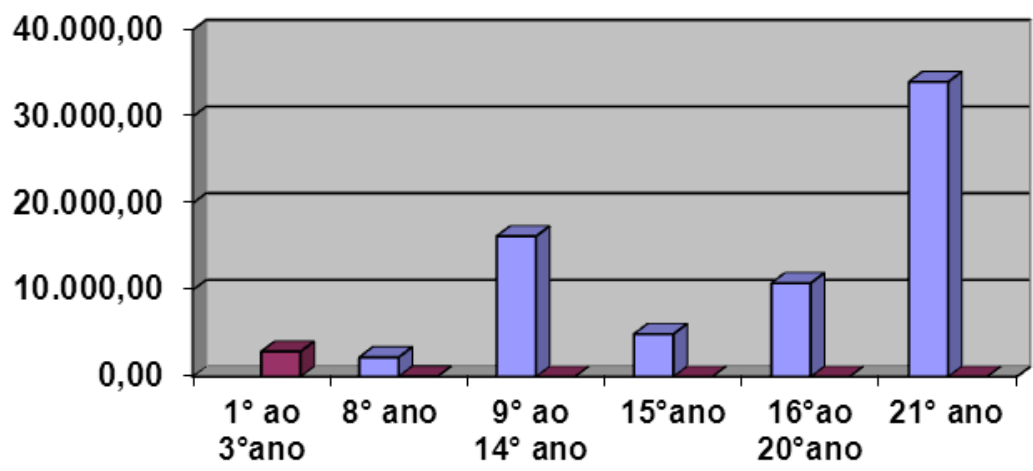

QRetorno Financeiro

- Investimento Inicial

Fonte: Elaborado pelos autores. 
Quadro 1 - Plano de Negocio para Implantação de pinus elliottii por hecta

\begin{tabular}{|c|c|c|c|c|c|c|c|c|c|c|c|c|c|c|c|c|c|c|c|c|c|}
\hline \multicolumn{22}{|c|}{ Ciclo de 0 a 21 anos } \\
\hline \multirow{2}{*}{ ATIVIDADES } & \multicolumn{3}{|c|}{ INVESTIMENTOS } & & & & & $\begin{array}{l}1^{\circ} \text { RECEITA } \\
\text { MADEIRA }\end{array}$ & \multicolumn{6}{|c|}{$2^{\circ}$ RECEITA RESINAGEM } & $\begin{array}{l}3^{\circ} \text { RECEITA } \\
\text { MADEIRA }\end{array}$ & \multicolumn{5}{|c|}{$4^{\circ}$ RECEITA RESINAGEM } & \multirow{2}{*}{$\begin{array}{c}\begin{array}{c}5^{\circ} \text { RECEITA } \\
\text { MADEIRA }\end{array} \\
21\end{array}$} \\
\hline & 1 & 2 & 3 & 4 & 5 & 6 & 7 & 8 & 9 & 10 & 11 & 12 & 13 & 14 & 15 & 16 & 17 & 18 & 19 & 20 & \\
\hline PREPARO DO SOLO & 1.650 & & & & & & & & & & & & & & & & & & & & \\
\hline PLANTIO & 250 & & & & & & & & & & & & & & & & & & & & \\
\hline PRIMEIRA MANUTENÇÃO & 200 & & & & & & & & & & & & & & & & & & & & \\
\hline SEGUNDA MANUTENÇÃO & & 200 & & & & & & & & & & & & & & & & & & & \\
\hline TERCEIRA MANUTENÇAOO & & 200 & & & & & & & & & & & & & & & & & & & \\
\hline QUARTA MANUTENÇÁO & & & 200 & & & & & & & & & & & & & & & & & & \\
\hline QUINTA MANUTENÇÁO & & & 200 & & & & & & & & & & & & & & & & & & \\
\hline $1^{\circ}$ DESB. - CELL. $-8^{\circ}$ ANO & & & & & & & & 2.240 & & & & & & & & & & & & & \\
\hline RESINAGEM $9^{\circ}$ ANO & & & & & & & & & 1.800 & & & & & & & & & & & & \\
\hline RESINAGEM $10^{\circ}$ ANO & & & & & & & & & & 2.400 & & & & & & & & & & & \\
\hline RESINAGEM $11^{\circ}$ ANO & & & & & & & . & & & & 3.000 & & & & & & & & & & \\
\hline RESINAGEM $12^{\circ}$ ANO & & & & & & & & & & & & 3.000 & & & & & & & & & \\
\hline RESINAGEM $13^{\circ}$ ANO & & & & & & & 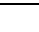 & & & & & & 3.000 & & & & & & & & \\
\hline RESINAGEM $14^{\circ}$ ANO & & & & & & & 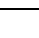 & & & & & & & 3.000 & & & & & & & \\
\hline $2^{\circ}$ DESB. - CEL. $-15^{\circ}$ ANO & & & & & & & & & & & & & & & 1.740 & & & & & & \\
\hline $2^{\circ}$ DESB. - TORA - $15^{\circ}$ ANO & & & & & & & & & & & & & & & 3.180 & & & & & & \\
\hline RESINAGEM $16^{\circ}$ ANO & & & & & & & & & & & & & & & & 2.160 & & & & & \\
\hline RESINAGEM $17^{\circ}$ ANO & & & & & & & & & & & & & & & & & 2.160 & & & & \\
\hline RESINAGEM $18^{\circ}$ ANO & & & & & & & & & & & & & & & & & & 2.160 & & & \\
\hline RESINAGEM $19^{\circ}$ ANO & & & & & & & & & & & & & & & & & & & 2.160 & & \\
\hline RESINAGEM $20^{\circ}$ ANO & & & & & & & & & & & & & & & & & & & & 2.160 & \\
\hline $3^{\circ}$ DESB. - CEL. - $21^{\circ}$ ANO & & & & & & & 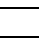 & & & & & & & & & & & & & & 2.000 \\
\hline $3^{\circ}$ DESB. - TORA - $21^{\circ}$ ANO & & & & & & & & & & & & & & & & & & & & & 32.000 \\
\hline TOTAL ANUAL & 2.100 & 400 & 400 & & & & & 2.240 & 1.800 & 2.400 & 3.000 & 3.000 & 3.000 & 3.000 & 4.920 & 2.160 & 2.160 & 2.160 & 2.160 & 2.160 & 34.000 \\
\hline & & & & & & & & RES & ULTAD & TOTAL & FINAL & DPERIO & & & & & & & & & 65.260 \\
\hline
\end{tabular}

SE APLICAR O CAPITAL DO INVESTIMENTO INICIAL DE ACORDO COM O PERÍODO CORRESPONDENTE, TERÍAMOS O SEGUINTE RESULTADO FINANCEIRO:

R\$2.100 - ANO 1 - POR 21 ANOS, A UMA TX EFETIVA DE 10\% AA: R\$15.540,00

R\$ 400 - ANO 2 - POR 20 ANOS, A UMA TX EFETIVA DE 10\% AA: R\$2.450,00

R\$ 400 - ANO 3 - POR 19 ANOS, A UMA TX EFETIVA DE 10\% AA: $\mathbf{R} \$ \mathbf{2 . 4 5 0 , 0 0}$

TOTAL SE OCORRESSE A APLICAÇÃO FINANCEIRA

$\mathbf{R} \$ 18.235,00$

SE APLICAR O CAPITAL DO INVESTIMENTO NO REFLORESTAMENTO TERIAMOS OS SEGUINTES RESULTADOS CONFORME O QUADRO 10 ACIMA:

INVESTIMENTOS INICIAIS: R\$2.900,00

RECEITA TOTAL COM REFLORESTAMENTO: $\mathbf{R} \$ 68.160,00$

TOTAL SE OCORRESSE A APLICAÇÃO FINANCEIRA $\quad$ R \$ 65.260,00

Considerando a Venda da Madeira em pé: Celulose $R \mathbf{R} 20,00$

Toras 15 anos $R \$ 60,00$

Toras 21 anos $R \$ 80,00$

\section{PORTANTO A CONCLUSÃO DO PLANO DE NEGÓCIO: VIÁVEL}

Fonte: Elaborado pelos autores. 


\section{CONSIDERAÇÕES FINAIS}

No contexto regional, as importâncias econômicas, sociais e ambientais são inquestionáveis na medida em que a cadeia florestal pode vir a ser uma forma de dinamizar a região em um novo eixo de desenvolvimento com mais participação social, produtores rurais, empresários do setor urbano e a população economicamente ativa, que às vezes não encontra ocupação na própria região.

O reflorestamento florestal em nível de propriedade e comunidades rurais constitui uma alternativa para o aumento da oferta de produtos florestais de forma planejada, organizada, sustentável e ambientalmente correto, capaz de promover o desenvolvimento integrado regional e o êxodo rural. O trabalho buscou apresentar a análise da viabilidade econômica por hectare mostrando uma lucratividade positiva no investimento com o reflorestamento de pinus, além e analisar todos os fatores da operacionalidade da implantação do reflorestamento na propriedade rural, quanto às dificuldades encontradas na região como, topografia do terreno, solos pobres, distância do mercado, estradas, situação econômica do produtor entre outros, através dessa análise pode-se concluir que o investimento com o reflorestamento é um investimento totalmente viável.

\section{REFERÊNCIAS}

ASSOCIAÇÃO BRASILEIRA DE PRODUTORES DE FLORESTAS PLANTADAS. Conselho de Informações de Biotecnologia. Anuário Estatístico da ABRAF - ano base 2008. Brasília, 2008 -

RIBEIRO, A. Monitorando o tempo e o clima a favor da silvicultura. In: ENCONTRO BRASILEIRO DE SILVICULTURA. Curitiba, 1. 10 a 12 nov. 2008. Anais... Piracicaba: Instituto de Pesquisas e Estudos Florestais, 2008. Disponível em: http://www.ipef.br/eventos/2008/ebs2008/16-aristides.pdf.

CAETANO, M. Madeira! Produtores de menor porte mostram que investir em florestas pode ser um bom negócio. Globo Rural, São Paulo n 260, jun. 2007. p. 65- 75.

DELLA LUCIA, T. M. C. (Ed). As Formigas cortadeiras. Viçosa: Folha da Mata, 1993. 262p.

CRISTIANO, D. A. Avaliação de imóveis rurais. Viçosa: Aprenda Fácil, 2002.p.203. (Exemplos Práticos De Avaliações Florestais).

SILVA, M. L.; JACOVINE, L. A.G.; VALVERDE, S. R. Economia florestal. 2.ed. Viçosa: UFV, 2002. 
Nucleus, v.9, n.2, out.2012 
